\title{
KINERJA PENYULUH PERTANIAN LAPANGAN TANAMAN PANGAN DI WILAYAH KERJA UPT KECAMATAN JATI AGUNG KABUPATEN LAMPUNG SELATAN
}

\author{
(Performance of Agricultural Extension Workers (AEWs) in Technical Implementation Area Unit \\ of Jati Agung Sub-District, Lampung Selatan District)
}

Shandy Andika, Begem Viantimala, Indah Nurmayasari

Jurusan Agribisnis, Fakultas Pertanian, Universitas Lampung, J1. Prof. Dr. Soemantri Brojonegoro No. 1 Bandar Lampung 35145, Telp. 082278605664.e-mail: Shandyandika200393@gmail.com

\begin{abstract}
The purposes of this study are to analyze level of Agricultural Extension Workers (AEWs)'s performance in Technical Implementation and factors related to the level of the performance in working area of Jati Agung Subdistrict of Lampung Selatan District,. This research was conducted in Jati Agung Subdistrict of Lampung Selatan District in September-October 2017. Respondents were 76 randomly selected rice farmers in the area. Data analysis uses descriptive analysis and Rank Spearman correlation test. The results indicated that the level of performance of AEWs in Technical Implementation is included ina medium category. Reward system is significantly related to the level of AEWs' performance, while motivation level, income level, education level, number of farmers, and distance of residency are not significantly related to the level of AEWs' performance in Technical Implementation Unit Jati Agung Subdistrict.
\end{abstract}

Key words: AEW, performance, Technical implementation unit

\section{PENDAHULUAN}

Sektor pertanian merupakan prioritas pembangunan di negara sedang berkembang. Pembangunan pertanian tersebut memiliki tujuan memperbaiki mutu konsumsi dan memenuhi kebutuhan bahan pangan secara nasional. Proses pembangunan pertanian menunjukkan secara nyata mengenai peranan pendidikan sebagai unsur yang esensial dalam proses pembangunan pertanian itu sendiri. Keberhasilan pembangunan pertanian itu sendiri ditentukan oleh kemampuan sumberdaya manusia dalam mengelola sistem pertanian yang sesuai dengan perkembangan ilmu pengetahuan dan teknologi. Oleh karena itu, pemberdayaan sumberdaya manusia di bidang pertanian perlu ditingkatkan melalui pendidikan, pelatihan, dan penyuluhan pertanian (Deptan 2008).

Menurut Departemen Pertanian (2006), dengan paradigma baru pembangunan pertanian yang arahnnya lebih melihat petani sebagai subyek atau pelaku pembangunan maka kelompok tani berperan sebagai lembaga petani yang dapat mengubah perilaku anggotanya untuk meningkatkan keberhasilan usahataninya dan dapat membawa anggotannya menjadi petani modern dengan mampu mengadopsi inovasi di bidang pertanian (Deptan 2006).

Kelembagaan penyuluhan pemerintah yang disebutkan dalam Undang Undang Republik
Indonesia Nomor 16 Tahun 2006 tentang Sistem Penyuluhan Pertanian, Perikanan, dan Kehutanan yaitu, pada tingkat pusat berbentuk badan yang menangani penyuluhan, pada tingkat Provinsi berbentuk Badan Koordinasi Penyuluhan Pertanian, Perikanan, dan Kehutanan (Bakorluh PPK), pada tingkat kabupaten atau kota berbentuk Badan Pelaksana Penyuluhan Pertanian, Perikanan, dan Kehutanan (BP4K) dan pada tingkat kecamatan berbentuk Balai Penyuluhan Pertanian, Perikanan, dan Kehutanan, BP3K dan pada saat ini sudah diubah pada tahun 2017 menjadi Unit Pelaksanaan Teknis (UPT) yaitu perubahan Susunan organisasi Tata Kerja (SOTK) berdasarkan peraturan Daerah Kabupaten Lampung Selatan Nomor 18 tahun 2016, UPT merupakan wadah bagi penyuluh di Kecamatan untuk melaksanakan berbagai aktivitas penyuluhan

Menurut UU No 23 Tahun 2014, peraturan yang dikeluarkan oleh pemerintah daerah atas perubahan susunan dan kewenangan daerah dari kepala daerah sampai dengan susunan kegiatan kerja pada daerah guna untuk terwujudnya kesejahteraan masyarakat. Keberadaan penyuluh di lingkungan masyarakat akan lebih membantu petani dalam menyelesaikan permasalahan yang dihadapi petani, khususnya dalam hal usahatani sebagai mata pencahariaan utama petani. 
Permasalahan pembangunan pertanian di Indonesia meliputi permasalahan lahan pertanian, infrastruktur, benih, regulasi atau kelembagaan, permodalan dan sumber daya manusia (SDM). Salah satu permasalahan dalam hal SDM adalah keterbatasan tenaga penyuluh pertanian baik dari segi kuantitas maupun kualitasnya. Oleh karena itu, arah kebijakan pembangunan pertanian tahun 2015-2019 yang dirumuskan untuk mengatasi permasalahan SDM tersebut adalah dengan meningkatkan kuantitas dan kualitas kinerja penyuluh pertanian tersebut . Menurut Peraturan Menteri Pertanian No. 91 Tahun 2013, untuk membangun SDM pertanian yang berkualitas dan handal, diperlukan kinerja penyuluh pertanian yang profesional, kreatif, inovatif, dan berwawasan Global.

Kecamatan Jati Agung merupakan salah satu yang menghadapi berbagai permasalahan pertanian seperti lahan pertanian, infrastuktur, benih, regulasi atau kelembagaan, permodalan. Sumberdaya manusia yang terdidik dalam hal ini petani akan dapat menghadapi berbagai permasalahan tersebut. Peran penyuluh dalam mengarahkan dan membina petani dalam menghadapi permasalahan yang ada menjadi sangat penting. Selain itu, pemerintah juga memberikan berbagai program untuk mengatasi permaslahan pertanian yang dihadapi, oleh karena itu sangat dibutuhkan kinerja penyuluh profesional, kreatif, inovatif, dan berwawasan Global untuk menghadapi permasalahan pertanian yang dihadapi.

Kinerja penyuluh dalam melaksanakan kegiatan meningkatkan produksi dan produktivitas tanaman Pangan, dengan kondisi kuantitas dan kualitas yang ada perlu dikaji, untuk mengetahui optimal atau tidaknya kinerja penyuluh di Kecamatan Jati Agung. Peningkatan kinerja menjadi sangat penting, karena sebagian besar UPT memiliki kinerja yang sangat memprihatikan. Menurut Effendi dan Sumaryo (dalam Ardiansyah 2014), rendahnya kinerja penyuluh pertanian dapat ditandai dengan rendahnya efektivitas kegiatan penyuluhan. Fungsi penyuluhan pertanian dalam masyarakat adalah menjembatani antara dunia ilmu dengan pelaksanan pembangunan. Lemahnya kinerja sebagian besar UPT tidak terlepas dari rendahnya kapasitas SDM yang ada, lemahnya kemampuan menyusun program jangka panjang dan berkelanjutan, serta lemahnya daya dukung biaya operasional (Sumaryo, Listiana dan Gultom 2012). Penelitian ini bertujuan untuk mengetahui tingkat kinerja penyuluh pertanian dan faktorfaktor yang berhubungan dengan tingkat kinerja penyuluh pertanian tanaman pangan di UPT Kecamatan Jati Agung Kabupaten Lampung Selatan.

\section{METODE PENELITIAN}

Metode yang digunakan dalam penelitian ini adalah metode survei yaitu metode penelitian yang mengambil sampel dari satu populasi dan menggunakan kuisioner sebagai alat pengumpul data yang pokok (Singarimbun dan Effendi 1989). Pengumpulan data dilakukan dengan wawancara langsung dan dokumentasi. Penelitian ini dilakukan pada bulan September-Oktober 2017. Data yang digunakan pada penelitian ini adalah data primer dan data sekunder. Data primer didapat dari hasil wawancara dengan menggunakan kuisioner, sedangkan data sekunder didapat dari instansi-instansi terkait dengan penelitian, yaitu wilayah kerja UPT Kecamatan Jati Agung, Dinas pertanian, dll. Dalam penelitian ini pemilihan sampel menggunakan metode acak sederhana (Simple Random Sampling). Petani padi di Kecamatan Jati Agung berjumlah 9.065 orang. Penentuan jumlah sampel secara proporsional berdasarkan teori Sugiarto, dkk (2003) dengan rumus sebagai berikut:

$\mathrm{n}=\frac{\mathrm{NZ}^{2} \mathrm{~S}^{2}}{\mathrm{Nd}^{2}+\mathrm{Z}^{2} \mathrm{~S}^{2}}$

Keterangan:

$\mathrm{n}=$ Jumlah sampel

$\mathrm{N}=$ Jumlah populasi petani (1.117 orang)

$\mathrm{Z}=$ Tingkat kepercayaan $(95 \%=1,96)$

$S^{2}=$ Variasi sampel $(5 \%=0,05)$

$\mathrm{d}=$ Derajat penyimpangan $(5 \%=0,05)$

Berdasarkan perhitungan dengan menggunakan rumus diatas, diperoleh jumlah sampel untuk petani padi di Kecamatan Jati Agung yaitu sebanyak 76 orang yang tersebar di 21 Gapoktan yang berada di wilayah kerja penyuluh pertanian Kecamatan Jati Agung. Berdasarkan dari jumlah petani yang diperoleh kemudian ditentukan alokasi proporsional sample petani yang ada di setiap wilayah kerja penyuluh pertanian dengan rumus (Nasir 1988), yaitu sebagai berikut :

$\mathrm{Na}=\frac{\mathrm{Na}}{\mathrm{N}} \mathrm{n}$

Keterangan :

na $=$ Jumlah sampel petani

$\mathrm{Na}=$ Jumlah populasi petani di kelompok tani

$\mathrm{N}=$ Jumlah populasi petani keseluruhan 
$\mathrm{n} \quad=$ Jumlah sampel petani keseluruhan.

Pengolahan data dilakukan dengan tabulasi dan analisis data dilakukan dengan menggunakan analisis deskriptif. Hipotesis pada penelitian ini diuji menggunakan analisis Rank Spearman. Uji korelasi Rank Spearman juga disebut uji korelasi berjenjang $\left(\mathrm{r}_{\mathrm{s}}\right)$. Kegunaan uji korelasi Rank Spearman adalah untuk mengukur tingkat keeratan hubungan antara dua variabel atau variabel bebas dengan variabel terikat yang berskala ordinal (Riduwan, 2010). Pada penelitian ini digunakan uji korelasi Rank Spearman karena (a) skala pengukuran data yang digunakan pada penelitian ini adalah skala ukur ordinal dan rasio, (b) data yang diteliti merupakan data berpasangan dari populasi yang sama, dan (c) jenis hipotesis yang digunakan yaitu hipotesis korelasi yang meramalkan derajad hubungan antara variabel $\mathrm{X}$ dan variabel $\mathrm{Y}$.

Menurut (Siegel 1986), rumus korelasi Rank Spearman yang digunakan yaitu sebagai berikut:

$r_{s}=1-\frac{6 \Sigma_{\mathrm{i}-1}^{\mathrm{u}} \mathrm{di}}{\mathrm{n}^{3}-\mathrm{n}}$

Kaidah pengambilan keputusan (Sulaiman 2003):

1. Jika $t_{\text {hitung }} \geq t_{\text {tabel }}$ atau jika sig. (2-tailed) $\leq \alpha / 2$, maka hipotesis diterima, pada $(\alpha)=0,05$ berarti terdapat hubungan antara kedua variabel yang diuji.

2. Jika $t_{\text {hitung }}<t_{\text {tabel }}$ atau jika sig. (2-tailed $>\alpha / 2$ ), maka hipotesis ditolak, pada $(\alpha)=0,05$ berarti tidak terdapat hubungan antara kedua variabel yang diuji.

\section{HASIL DAN PEMBAHASAN}

\section{Gambaran Umum Kecamatan Jati Agung}

Kecamatan Jati Agung secara geografis berjarak 70 $\mathrm{Km}$ dari pusat pemerintahan Kabupaten Lampung Selatan dan berjarak $15 \mathrm{Km}$ dari Kota Bandar Lampung (Ibukota Provinsi Lampung). Kecamatan Jati Agung memiliki luas wilayah 4.635 Ha. Kecamatan Jati Agung berada pada ketinggian 47-110 mdpl. Jenis tanah di Kecamatan Jati Agung yaitu Podsolid merah kuning dengan $\mathrm{pH}$ tanah berkisar 4,9-5,9. Suhu udara rata-rata di Kecamatan Jati Agung adalah $30-35^{\circ} \mathrm{C}$.

\section{Gambaran Umum UPT Kecamatan Jati Agung}

UPT Kecamatan Jati Agung yang berdiri pada tahun 2009 melalui dana DAK dan Pendampingan bidang pertanian yang terletak di Desa Fajar Baru Kecamatan Jati Agung, pada tahun 2017 terjadi perubahan susunan Organisasi Tata Kerja (SOTK) yang semulanya BP3K menjadi UPT yang disebut Unit Pelaksanaan Teknis sesuai dengan PP Nomor 18 tahun 2016 tentang peraturan daerah. Luas lahan UPT Kecamatan Jati Agung $5.015 \mathrm{~m}^{2}$, digunakan untuk Bangunan Kantor UPT, Aula, Perumahan Dinas, Kolam ikan, Tanaman padi sawah dan sayuran.

\section{Keadaan Umum Responden}

Responden pada penelitian ini adalah PPL dan petani padi sawah yang tergabung dalam Gapoktan di Kecamatan Jati Agung. Sampel penyuluh pertanian berjumlah 10 orang dipilih secara sengaja (purposive sampling ) yaitu hanya penyuluh pertanian yang fokus utama pekerjaannya pada bidang komoditas tanaman pangan dan memiliki petani binaan dari wilayah binaan yang telah ditentukan. Jumlah petani sampel dipilih dari 10 WKPP sebanyak 76 responden.

\section{Faktor - Faktor Berhubungan dengan Tingkat Kinerja PPL di UPT Kecamatan Jati Agung Kabupaten Lampung Selatan (X)}

Faktor-faktor yang diduga berhubungan dengan tingkat kinerja PPL di UPT Kecamatan Jati Agung adalah tingkat motivasi PPL, tingkat pendapatan PPL, tingkat pendidikan PPL, jumlah petani binaan PPL, sistem penghargaan yang diberikan kepada PPL dan jarak tempat tinggal PPL dengan wilayah binaan. Penjelasan faktor-faktor yang diduga berhubungan dengan tingkat kinerja PPL di UPT Kecamatan Jati Agung adalah sebagai berikut

Tabel 1. Sebaran tingkat motivasi PPL di BP3K Kecamatan Jati Agung

\begin{tabular}{llll}
\hline \multirow{2}{*}{ Interval (Skor) } & \multirow{2}{*}{ Klasifikasi } & \multicolumn{2}{l}{ Jumlah responden } \\
\cline { 3 - 4 } & & Jiwa & Persentase $(\%)$ \\
\hline $18,353-20,651$ & Rendah & 5 & 50,00 \\
$20,652-22,950$ & Sedang & 3 & 30,00 \\
$22,951-25,247$ & Tinggi & 2 & 20,00 \\
\hline Jumlah & 10 & \\
Rata-Rata : 21,104 (sedang) & & \\
\hline
\end{tabular}


Tingkat Motivasi PPL (X1)

Motivasi PPL di UPT Kecamatan Jati Agung tergolong pada klasifikasi sedang dengan nilai ratarata 21,104 dan persentase tergolong 50 persen untuk total penyuluh.

\section{Tingkat Pendapatan PPL (X2)}

Tingkat Pendapatan PPL di UPT Kecamatan Jati Agung tergolong pada klasifikasi sedang dengan nilai rata-rata Rp2.970.000 sebanyak 60 persen. Pendapatan PPL di Kecamatan Jati Agung lebih rendah dibandingkan dengan pendapatan nasional per kapita Tahun 2017. Pendapatan nasional per kapita Tahun 2017 adalah sebesar Rp44.360.000/tahun atau sebesar Rp3.700.000/bulan. Pendapatan PPL disajikan pada Tabel 2.

\section{Tingkat Pendidikan PPL (X3)}

Tingkat pendidikan formal PPL di UPT Kecamatan Jati Agung terdiri dari Diploma (D3) dan Sarjana (S1) serta SLTA. Sebagian (50\%) responden PPL pada penelitian ini memiliki pendidikan Sarjana (S1), dengan lama tahun sukses menjalani pendidikan formal selama 16 tahun yang termasuk dalam klasifikasi tinggi. Pendidikan PPL disajikan pada Tabel 3.

\section{Jumlah Petani Binaan (X4)}

Jumlah petani binaan PPL di UPT Kecamatan Jati Agung paling banyak yaitu 950 petani. Rata-rata jumlah petani binaan PPL di UPT Kecamatan Jati Agung yaitu sebanyak 520 petani. Jumlah tersebut melebihi standar atau tidak ideal dengan rentang kendali PPL yakni seorang PPL idealnya membina 160 sampai 400 petani. Menurut Undang-undang Tahun 2013 tentang perlindungan dan pemberdayaan petani. Jumlah petani binaan PPL disajikan pada Tabel 4.

Tabel 2. Sebaran jumlah PPL berdasarkan tingkat pendapatan

\begin{tabular}{|c|c|c|c|}
\hline \multirow{2}{*}{$\begin{array}{c}\text { Interval } \\
\text { (Rp/bulan) }\end{array}$} & \multirow[b]{2}{*}{ Klasifikasi } & \multicolumn{2}{|c|}{ Jumlah responden } \\
\hline & & Jiwa & $\begin{array}{c}\text { Persentase } \\
(\%)\end{array}$ \\
\hline $\begin{array}{l}1.100 .000-2.566 .666,67 \\
2.566 .666,68-\end{array}$ & Rendah & 6 & 60,00 \\
\hline $4.033 .333,35$ & Sedang & 1 & 10,00 \\
\hline $4.033 .333,36-5.500 .000$ & Tinggi & 3 & 30,00 \\
\hline $\begin{array}{l}\text { Jumlah } \\
\text { Rata-rata: Rp 2.970.000/bu }\end{array}$ & n (Rendah) & & 100,00 \\
\hline
\end{tabular}

Tabel 3. Keadaan umum responden PPL berdasarkan tingkat pendidikan

\begin{tabular}{cccc}
\hline Tingkat Pendidikan & Jumlah (Jiwa) & Persentase $(\%)$ \\
\hline & S1 & 5 & 50,00 \\
& D3 & 4 & 40,00 \\
& SMA & 1 & 10,00 \\
\hline Total & & 10 & 100,00 \\
\hline
\end{tabular}

\section{Sistem Penghargaan yang Diberikan Kepada PPL (X5)}

Nilai rata-rata sistem penghargaan kepada PPL di UPT Kecamatan Jati Agung yaitu 21,330 yang tergolong sedang. Hal tersebut dikarenakan terdapat PPL yang jarang melakukan kunjungan ke kelompok tani binaan dan jarang melengkapi administrasi. Sistem penghargaan PPL disajikan pada Tabel 5.

\section{Jarak Tempat Tinggal PPL dengan WKPP (X6)}

Jarak tempat tinggal PPL $\left(\mathrm{X}_{6}\right)$ adalah rentang jarak tempat tinggal seorang PPL dengan wilayah binaan. Jarak tempat tinggal PPL dengan WKPP yang paling jauh yaitu $45 \mathrm{~km}$, sedangkan jarak tempat tinggal yang paling dekat yaitu $3 \mathrm{~km}$. Ratarata jarak tempat tinggal PPL dengan WKPP di Kecamatan Jati Agung yaitu $24 \mathrm{~km}$. Jarak tempat tinggal PPL disajikan pada Tabel 6.

\section{Tingkat Kinerja PPL di UPT Kecamatan Jati Agung (Y)}

Tingkat kinerja PPL pada penelitian ini diukur menggunakan tiga indikator yaitu persiapan penyuluhan pertanian, pelaksanaan penyuluhan pertanian, evaluasi dan pelaporan penyuluhan pertanian. Berdasarkan Tabel 7 , rata-rata skor tingkat kinerja penyuluhan pertanian di UPT Kecamatan Jati Agung yaitu 28,616 yang termasuk pada klasifikasi sedang. Pada persiapan penyuluhan pertanian, PPL di UPT Kecamatan Jati Agung tidak melibatkan anggota kelompok tani untuk menyusun persiapan penyuluhan pertanian melainkan hanya melibatkan pengurus kelompok tani saja. Pada pelaksanaan penyuluhan pertanian, PPL di UPT Kecamatan Jati Agung rajin mengunjungi kelompok tani yang aktif saja biasanya PPL merekomendasikan kelompok tani yang aktif tersebut. Hasil ini sama dengan penelitian Sari (2017) yang menyatakan bahwa secara keseluruhan kinerja penyuluh pertanian dalam melaksanakan tugas pokok penyuluh pertanian di UPT Kecamatan Banjar Baru Kabupaten Tulang Bawang termasuk dalam klasifikasi sedang 
Tabel 4. Sebaran jumlah PPL berdasarkan jumlah petani binaan

\begin{tabular}{llcc}
\hline \multirow{2}{*}{$\begin{array}{c}\text { Interval } \\
\text { jumlah petani binaan }\end{array}$} & Klasifikasi & \multicolumn{2}{c}{ Jumlah responden } \\
\cline { 3 - 4 } & & Jiwa & $\begin{array}{c}\text { Persentase } \\
(\%)\end{array}$ \\
\hline $251-484$ & Sedikit & 5 & 50,00 \\
$485-718$ & Sedang & 4 & 40,00 \\
$719-950$ & Banyak & 1 & 10,00 \\
\hline Jumlah & 10 & 100,00 \\
Rata-rata: 520 petani binaan (sedang) & & \\
\hline
\end{tabular}

\section{Pengujian Hipotesis}

Hubungan antara faktor-faktor yang berhubungan dengan tingkat kinerja PPL di UPT Kecamatan Jati Agung yang dianalisis menggunakan uji korelasi Rank Spearman. Uji korelasi Rank Spearman dioperasikan dengan bantuan Program SPSS 16.0. Faktor-faktor yang berhubugan dengan tingkat kinerja penyuluh tingkat kinerja PPL di UPT Kecamatan Jati Agung meliputi tingkat motivasi PPL $\left(\mathrm{X}_{1}\right)$, tingkat pendapatan PPL $\left(\mathrm{X}_{2}\right)$, tingkat pendidikan PPL $\left(\mathrm{X}_{3}\right)$, jumlah petani binaan PPL $\left(\mathrm{X}_{4}\right)$, sistem penghargaan yang diberikan kepada PPL $\left(\mathrm{X}_{5}\right)$, dan jarak tempat tinggal PPL dengan $\operatorname{WKPP}\left(\mathrm{X}_{6}\right)$.

Hasil ini sama dengan penelitian Santi (2016) yang menyatakan bahwa faktor internal yang meliputi tingkat motivasi, tingkat pendapatan dan tingkat pendidikan tidak berhubungan nyata dengan tingkat kinerja penyuluh pertanian di BP3K Kecamatan Gadingrejo.

Faktor eksternal yang meliputi jumlah petani binaan dan jarak tempat tinggal tidak berhubungan nyata, sedangkan faktor eksternal lainnya yaitu sistem penghargaan berhubungan nyata dengan tingkat kinerja penyuluh pertanian di BP3K Kecamatan Gadingrejo. Hasil pengujian hubungan antara faktor-faktor yang berhubugan dengan kinerja penyuluh terhadap tingkat kinerja PPL di UPT Kecamatan Jati Agung dapat dilihat pada Tabel 8.

Tabel 5. Sebaran hasil penilaian PPL di BP3K Kecamatan Jati Agung terhadap sistem penghargaan

\begin{tabular}{llll}
\hline \multirow{2}{*}{ Interval (Skor) } & \multirow{2}{*}{ Klasifikasi } & \multicolumn{2}{c}{ Jumlah responden } \\
\cline { 3 - 4 } & & Jiwa & Persentase (\%) \\
\hline $19,516-20,996$ & Rendah & 4 & 40,00 \\
$20,997-22,477$ & Sedang & 4 & 40,00 \\
$22,478-23,956$ & Tinggi & 2 & 20,00 \\
\hline Jumlah & & 10 & 100,00 \\
Rata-Rata $=21,330$ (Sedang) & & \\
\hline
\end{tabular}

Tabel 6. Sebaran jumlah PPL berdasarkan jarak tempat tinggal dengan WKPP

\begin{tabular}{llll}
\hline \multicolumn{1}{c}{$\begin{array}{c}\text { Interval } \\
(\mathrm{km})\end{array}$} & \multirow{2}{*}{ Klasifikasi } & \multicolumn{2}{c}{ Jumlah responden } \\
\cline { 3 - 4 } & & Jiwa & Persentase $(\%)$ \\
\hline $27-35$ & Jauh & 1 & 10,00 \\
$16-26$ & Sedang & 5 & 50,00 \\
$5-15$ & Dekat & 4 & 40,00 \\
\hline Jumlah & & 10 & 100,00 \\
Rata-rata: $24 \mathrm{~km}$ & & & \\
\hline
\end{tabular}

\section{Hubungan antara tingkat motivasi PPL dengan tingkat kinerja PPL di UPT Kecamatan Jati Agung}

Berdasarkan hasil pengujian hipotesis hubungan antara tingkat motivasi PPL dengan tingkat kinerja PPL, menunjukkan bahwa tingkat motivasi PPL tidak berhubungan nyata dengan tingkat kinerja PPL di UPT Kecamatan Jati Agung dengan nilai signifikan sebesar 0,090 lebih besar dari $\alpha(0,05)$. Hal ini karena motivasi PPL berkelompok pada klasifikasi tertentu yaitu klasifikasi rendah sebanyak $50 \%$.

Hubungan antara tingkat pendapatan PPL dengan tingkat kinerja PPL di UPT Kecamatan Jati Agung

Berdasarkan hasil pengujian hipotesis hubungan antara tingkat pendapatan PPL dengan tingkat kinerja PPL, diperoleh hasil bahwa tingkat pendapatan PPL tidak berhubungan nyata dengan tingkat kinerja PPL di UPT Kecamatan Jati Agung dengan nilai signifikan sebesar 0,165 lebih besar dari $\alpha(0,05)$ artinya tingkat pendapatan PPL tidak berhubungan nyata dengan tingkat kinerja PPL di UPT Kecamatan Jati Agung. Hasil penelitian ini tidak sejalan dengan penelitian Simanungkalit (2014) yang berjudul Faktor-faktor yang Mempengaruhi Kinerja Penyuluh UPT Padang Cermin Kabupaten Pesawaran sebagai UPT Center of Exellence yang menyimpulkan bahwa tingkat pendapatan rumah tangga PPL berpengaruh terhadap tingkat kinerja PPL di UPT Padang Cermin.

Tabel 7. Tingkat kinerja PPL di UPT Kecamatan Jati Agung secara keseluruhan menurut petani

\begin{tabular}{llll}
\hline \multirow{2}{*}{ Interval } & \multirow{2}{*}{ Klasifikasi } & \multicolumn{2}{c}{ Penyuluh dan petani } \\
\cline { 3 - 4 } & & Jiwa & Persentase $(\%)$ \\
\hline $24,371-27,064$ & Rendah & 3 & 30,00 \\
$27,065-29,758$ & Sedang & 4 & 40,00 \\
$29,759-32,452$ & Tinggi & 3 & 30,00 \\
\hline Jumlah & & 10 & 100,00 \\
Rata-Rata: 28,616 (sedang) & & \\
\hline
\end{tabular}


Tabel 8. Hasil analisis korelasi Rank Spearman antara faktor-faktor yang berhubungan dengan tingkat kinerja PPL terhadap tingkat kinerja PPL di UPT Kecamatan Jati Agung

\begin{tabular}{llll}
\hline \multicolumn{1}{c}{ Variabel X } & Variabel Y & $\begin{array}{c}\text { Koefisien } \\
\text { korelasi }\left(\mathrm{r}_{\mathrm{s}}\right)\end{array}$ & $\begin{array}{c}\text { sig. } \\
(2- \\
\text { tailed })\end{array}$ \\
\hline Tingkat motivasi & & 0,564 & 0,090 \\
Tingkat pendapatan & Tingkat kinerja & $-0,476$ & 0,165 \\
Tingkat pendidikan & penyuluhan & $-0,506$ & 0,135 \\
Jumlah petani binaan & pertanian & $-0,067$ & 0,854 \\
Sistem penghargaan & & $0,697^{*}$ & 0,025 \\
Jarak tempat tinggal & & 0,225 & 0,532 \\
\hline Keterangan: & & \\
$\mathrm{r}_{\mathrm{s}} \quad$ : Rank Spearman & & \\
$*$ & : Nyata pada taraf kepercayaan $95 \%(\alpha=0,05)$ & \\
tn : Tidak nyata pada taraf kepercayaan $95 \%$ dan $99 \%$ & \\
\end{tabular}

Hubungan antara tingkat pendidikan PPL dengan tingkat kinerja PPL di UPT Kecamatan Jati Agung

Berdasarkan hasil pengujian hipotesis hubungan antara tingkat pendidikan PPL dengan tingkat kinerja PPL, diperoleh hasil nilai signifikan sebesar 0,135 lebih besar dari $\alpha(0,05)$ artinya tingkat pendidikan PPL tidak berhubungan nyata dengan tingkat kinerja PPL di UPT Kecamatan Jati Agung. Hal tersebut dikarenakan 60\% PPL di UPT Kecamatan Jati Agung memiliki tingkat pendidikan formal S1 dengan lama tahun sukses menjalani pendidikan formal selama 16 tahun. Penelitian ini tidak sejalan dengan hasil penelitian

Sapar (2012) yang berjudul Faktor-faktor yang Berpengaruh Pada Kinerja Penyuluh Pertanian dan Dampaknya Pada Kompetensi Petani Kakao di Empat Wilayah Sulawesi Selatan yang menyimpulkan bahwa salah satu faktor yang dapat meningkatkan kinerja PPL di Empat wilayah Sulawesi Selatan adalah tingkat pendidikan penyuluh pertanian.

Hubungan antara jumlah petani binaan PPL dengan tingkat kinerja PPL di UPT Kecamatan Jati Agung

Berdasarkan hasil pengujian hipotesis hubungan antara jumlah petani binaan PPL dengan tingkat kinerja PPL, diperoleh hasil bahwa jumlah petani binaan tidak berhubungan nyata dengan tingkat kinerja PPL di UPT Kecamatan Jati Agung dengan nilai signifikan sebesar 0,154 lebih besar dari $\alpha$ $(0,05)$.
Hubungan antara sistem penghargaan yang diberikan kepada PPL dengan tingkat kinerja PPL di UPT Kecamatan Jati Agung

Berdasarkan hasil pengujian hipotesis hubungan antara sistem penghargaan yang diberikan kepada PPL, diperoleh hasil bahwa sistem penghargaan yang diberikan kepada PPL berhubungan nyata dengan tingkat kinerja PPL di UPT Kecamatan Jati Agung dengan nilai signifikan sebesar 0,025 lebih kecil dari $\alpha(0,05)$, sistem penghargaan yang diberikan sudah tepat sasaran dan sesuai dengan disiplin kerja PPL. PPL menganggap bahwa dengan adanya sistem penghargaan dapat meningkatkan kinerja PPL.

Hubungan antara jarak tempat tinggal PPL dengan tingkat kinerja PPL di UPT Kecamatan Jati Agung

Hasil tingkat jarak tempat tinggal PPL tidak berhubungan nyata dengan tingkat kinerja PPL di UPT Kecamatan Jati Agung dengan nilai signifikan sebesar 0,532 lebih besar dari $\alpha(0,05)$ artinya jarak tempat tinggal PPL tidak berhubungan nyata dengan tingkat kinerja PPL di BP3K Jati Agung. Hal ini karena jarak tempat tinggal PPL berkelompok pada klasifikasi tertentu yaitu klasifikasi sedang sebanyak 50\%.

\section{KESIMPULAN}

Berdasarkan hasil penelitian dapat disimpulkan bahwa tingkat kinerja PPL di Kecamatan Jati Agung termasuk dalan klasifikasi sedang. Tingkat kinerja PPL pada indikator persiapan penyuluhan pertanian berada pada klasifikasi tinggi, indikator pelaksanaan penyuluhan pertanian berada pada klasifikasi sedang, evaluasi dan pelaporan penyuluhan pertanian berada pada klasifikasi tinggi. Faktor yang berhubungan dengan tingkat kinerja PPL di UPT Kecamatan Jati Agung yaitu sistem penghargaan, sedangkan faktor yang tidak berhubungan yaitu tingkat motivasi, pendapatan, pendidikan, jumlah petani binaan, dan jarak tempat tinggal PPL.

\section{DAFTAR PUSTAKA}

Ardiansyah A, Sumaryo, dan Yanfika H. 2014. Persepsi petani terhadap kinerja penyuluh di BP3K sebagai model COE (Center of Excellence) Kecamatan Metro Barat Kota Metro. JIIA, 2 (2) : 182-189. http://jurnal. fp. unila.ac.id/index.php/JIA/article/view/743/68 4. [8 September 2018]. 
Badan Pusat Penyuluhan Pertanian. 2015. Pelaksanaan Penggunaan Dana Dekonsentrasi Penyelenggaraan Penyuluhan Pertanian. Jakarta. Kementrian Pertanian

Badan Pusat Stastistik. 2015. Perkembangan Luas Panen, Produksi dan Produktivitas Padi. Lampung: BPS

Deptan. 2006. Undang-undang Republik Indonesia No. 16 Tahun 2006 tentang Sistem Penyuluhan Pertanian, Perikanan dan Kehutanan. Deptan. Jakarta.

2008. Pedoman Kerja Penyuluh Pertanian. Deptan. Jakarta

Kementerian Pertanian. 2013. Peraturan Menteri Pertanian Nomor 91/Permentan/ OT. 140/9/2013 Tentang Pedoman Evaluasi Kinerja Penyuluh Pertanian. Kementan. Jakarta.

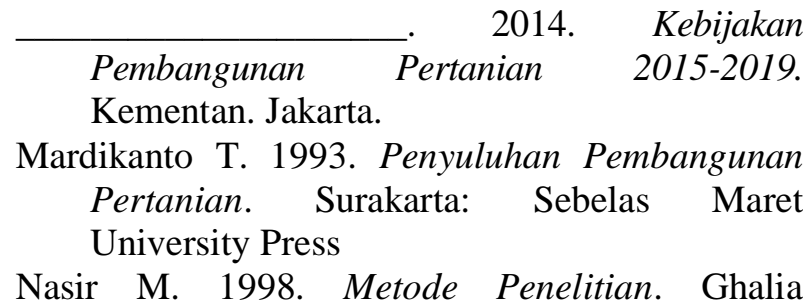
Indonesia. Jakarta.

Riduwan. 2010. Metodedan Teknik Menyusun Tesis. PT Alfabeta. Bandung.

Santi, Nikmatullah D, dan Prayitno RT. 2016. Tingkat kinerja penyuluh pertanian tanaman pangan di BP3K Kecamatan Gadingrejo Kabupaten Pringsewu. JIIA, 4 (3) : 309-316. http://jurnal.fp.unila.ac.id/index.php/JIA/articl e/view/1506/1360. [8 September 2018].
Sapar. 2012. Faktor-faktor yang berpengaruh pada kinerja penyuluh pertanian dan dampaknya pada kompetensi petani kakao di empat wilayah Sulawesi Selatan. Jurnal Penyuluhan. Vol. 8 (1).IPB. Bogor.

Sari DA, Nikmatullah D, dan Silviyanti S. 2017. Kinerja penyuluh pertanian lapangan dalam melaksanakan tugas pokok penyuluh di BP3K Kecamatan Banjar Baru Kabupaten Tulang Bawang. JIIA, 5 (4) : 438-445. http://jurnal.fp. unila.ac.id/index.php/JIA/article/view/1754/1 557. [8 September 2018].

Sari J, Nurmayasari I, dan Yanfika H. 2015. Persepsi petani terhadap kinerja penyuluh dalam pengembangan padi organik di Kecamatan Pagelaran Kabupaten Pringsewu. JIIA, 3 (4) : 432-439. http://jurnal.fp.unila.ac .id/ index.php/ JIA/article/view/1094/999. [8 September 2018].

Siegel S. 1986. Statistik Non-Parametrik Ilmu-ilmu Sosial. PT Gramedia Pustaka Utama. Jakarta

Simanungkalit YV. 2014. Faktor-faktor yang mempengaruhi kinerja penyuluh di BP3K Padang Cermin Kabupaten Pesawaran sebagai BP3K model CoE. Skripsi. Universitas Lampung. Bandar Lampung.

Singarimbun M dan S Effendi .1989. Metode Penelitian Survai. LP3ES. Jakarta.

Sumaryo, Listiana I, dan Gultom DT. 2012. DasarDasar Penyuluhan Dan Komunikasi Pertanian. Anugrah Utama Raharja. Bandar Lampung

Sugiarto, D Siagian, LT Sunaryanto, dan DS Oetomo. 2003. Teknik Sampling.PT. Gramedia Pustaka Utama. Jakarta. 